\title{
The variability of reported salt levels in fast foods across six countries: opportunities for salt reduction
}

\author{
Elizabeth Dunford MPH, Jacqueline Webster PhD, Mark Woodward PhD, Sebastien Czernichow PhD, \\ Wen Lun Yuan MPH, Katharine Jenner MPH, Cliona Ni Mhurchu PhD, Michael Jacobson PhD, \\ Norm Campbell MD, Bruce Neal PhD
}

\begin{abstract}
- AbSTRACT
Background: Several fast food companies have made commitments to reduce the levels of salt in the foods they serve, but technical issues are often cited as a barrier to achieving substantial reductions. Our objective was to examine the reported salt levels for products offered by leading multinational fast food chains.
\end{abstract}

Methods: Data on salt content for products served by six fast food chains operating in Australia, Canada, France, New Zealand, the United Kingdom and the United States were collected by survey in April 2010. Mean salt contents (and their ranges) were calculated and compared within and between countries and companies.

Results: We saw substantial variation in the mean salt content for different categories of products. For example, the salads we included in our survey contained $0.5 \mathrm{~g}$ of salt per $100 \mathrm{~g}$, whereas the chicken products we included contained $1.6 \mathrm{~g}$. We also saw variability between countries: chicken products from the UK contained $1.1 \mathrm{~g}$ of salt per $100 \mathrm{~g}$, whereas chicken products from the US contained $1.8 \mathrm{~g}$. Furthermore, the mean salt content of food categories varied between companies and between the same products in different countries (e.g., McDonald's Chicken McNuggets contain $0.6 \mathrm{~g}$ of salt per $100 \mathrm{~g}$ in the UK, but $1.6 \mathrm{~g}$ of salt per $100 \mathrm{~g}$ in the US).

Interpretation: The salt content of fast foods varies substantially, not only by type of food, but by company and country in which the food is produced. Although the reasons for this variation are not clear, the marked differences in salt content of very similar products suggest that technical reasons are not a primary explanation. In the right regulatory environment, it is likely that fast food companies could substantially reduce the salt in their products, translating to large gains for population health.
I $\mathrm{t}$ is widely accepted that excess dietary salt causes blood pressure to increase, and that salt is a major determinant of population blood pressure levels., ${ }^{1,2}$ Recent estimates suggest that the numbers of deaths averted by moderate reductions in population salt consumption would be at least as many as those achieved by plausible reductions in population smoking rates. ${ }^{3}$ In western countries, more than threequarters of dietary salt derives from processed foods. ${ }^{4}$ Coupled with rising rates of nutritionrelated diseases worldwide, ${ }^{5,6}$ the food industry has an increasingly important role to play in public health. With consumers now purchasing larger numbers of meals outside the home, fast food increasingly contributes to population intake of dietary salt. ${ }^{7,8}$ Fast food tends to be more energy dense, contain more saturated fat and salt, contain fewer micronutrients and be eaten in larger portions than other foods. ${ }^{9-11}$ Fast food items such as fried potatoes, pizzas and sugar-sweetened soft drinks typically provide between one-third and one-half of daily energy intake but less than one-quarter of most micronutrients. ${ }^{?}$

A number of leading multinational fast food companies have shown their ability to reformulate foods to reduce salt levels. The United Kingdom's Food Standards Agency and the New York City Health Department now have voluntary salt reduction targets in place for packaged foods, ${ }^{12,13}$ and the National Salt Reduction Initiative in the United States has set targets for salt reduction for 25 categories of foods in restaurants.

Technical feasibility is often cited by industry
Competing interests: See end of article.

This article has been peer reviewed.

Correspondence to:

Elizabeth Dunford, edunford@georgeinstitute .org.au

CMAJ 2012. DOI:10.1503 /cmaj.111895 
as an impediment to efforts to reduce salt content, with new processes and technologies required to deliver lower-salt products. ${ }^{14}$ There is, however, little evidence to verify whether industry has reached the technical limits of salt reduction. A survey of the salt levels in fast foods would provide insight into this issue by quantifying the variability in the salt levels of similar products produced by different companies in different countries.

We sought to compile current data on salt content for products offered by six leading transnational fast food chains and to compare the results between companies, countries and products.

\section{Methods}

We conducted a survey of the reported salt content of menu items from six fast food chains in Australia, Canada, France, New Zealand, the UK and the US. We collected these data in April 2010.

\section{Fast food companies}

We included foods from six companies: Burger King (known as Hungry Jack's in Australia), Domino's Pizza, Kentucky Fried Chicken, McDonald's, Pizza Hut and Subway. We selected these companies because they are the largest transnational fast food chains, ${ }^{15}$ they operate in the countries from which we (the investigators) derive, and they provide easily accessible data on their products' nutrition on the Internet.

\section{Product categories}

We included foods from seven categories in our survey: savoury breakfast items, burgers, chicken products, pizza, salads, sandwiches and french fries. The definitions used for these categories were based on those used for previous reports from the US ${ }^{16}$ and Australia, ${ }^{17}$ which had been derived from the categorizations commonly used by the fast food industry. Briefly, savoury breakfast items included breakfast burgers, rolls, sandwiches and hash browns. Burgers included all burger products not on the breakfast menu. Sandwiches included all sandwich items, rolls and wraps not on the breakfast menu. Chicken products included nuggets, drumsticks, and fried, grilled or roasted chicken. Salads included all salad items and salads with additional ingredients.

\section{Data collection}

We obtained data from the companies' websites in each participating country and entered them in an Excel spreadsheet. We recorded the company name, product name, serving size (grams) and the base salt content (grams) for each menu item we included. When such information was available, we recorded salt content both per serving and per $100 \mathrm{~g}$. When both values were not provided, we calculated one from the other using the serving size of the item. When information on sodium content was provided rather than salt content, we converted the value by multiplying by 2.5 (i.e., the atomic weight of sodium is 23 , whereas the molecular weight of sodium chloride [salt] is 58.5). We checked the accuracy of our process for entering the data by selecting a random sample of $5 \%$ of the entries and comparing the information in our database against the original source. We identified three minor errors, none of which had a substantive effect on our conclusions. In addition, we subjected all data to a series of range and logic checks.

\section{Statistical analysis}

We calculated the mean levels and ranges for salt content for each food category overall and separately for each company and country. We made separate estimates per serving and per $100 \mathrm{~g}$. When we saw evidence of differences between mean levels of salt per $100 \mathrm{~g}$ across countries, both overall and within categories of products, we tested the results using linear mixed models, allowing for the clustering of products by manufacturer. We evaluated pairwise comparisons using the Tukey-Kramer adjustment for multiple testing. We compared categories of products in the same way, both overall and by country. We used one-way analysis of variance to compare categories of products between companies, again using the Tukey-Kramer adjustment. We considered a $p$ value of 0.05 or less as unlikely to have arisen solely by chance.

\section{Results}

We collected data on the salt content of 2124 fast food items in seven product categories from six companies operating in six countries. The number of products in a category ranged from 41 (french fries) to 1108 (pizzas). Product categories varied significantly in their mean salt content $(p<0.001)$ (Table 1$)$, with chicken products having the highest mean level of salt (1.6 g salt per $100 \mathrm{~g})$ and salads having the lowest $(0.5 \mathrm{~g}$ salt per $100 \mathrm{~g}$ ). This variability in salt content between product categories was apparent in every country (all $p<0.001$ ), with a broadly similar pattern in each (Table 1). 


\section{Variation in salt content between countries}

There was considerable variability between countries in the salt content of products in the same categories. For example, the mean salt content per $100 \mathrm{~g}$ for savory breakfast items was significantly lower in the UK $(1.4 \mathrm{~g})$, Australia (1.3 g) and New Zealand $(1.1 \mathrm{~g})$ than in the US (1.8 g) (all $p<0.001$ ), and chicken products in the UK were significantly lower in salt $(1.1 \mathrm{~g}$ salt per $100 \mathrm{~g})$ than in the US $(1.8 \mathrm{~g})(p<0.001)$. In addition, we found that individual items marketed as the same product had very different levels of salt in different countries (Table 2). For example, McDonald's Chicken McNuggets had two and one-half times more salt in the US than in the UK (1.6 v. $0.6 \mathrm{~g}$ salt per $100 \mathrm{~g})$.

\section{Variation in salt content within product categories}

There was marked variation in the salt content of products within each of the seven categories studied, with a fivefold or greater difference in the salt content per $100 \mathrm{~g}$ between the least salty and the most salty product in each category. The average salt content of the same product category also varied considerably between companies $(p \leq 0.02)$ (Table 3$)$. For example, the mean salt level in sandwiches was $70 \%$ higher in Pizza Hut products than in Subway $(p<0.001)$.

\section{Variation in salt content per serving}

There was much greater variability when salt levels were reported per serving rather than per $100 \mathrm{~g}$ (Figure 1), reflecting nonstandard serving sizes between countries and between companies. For most product categories, the range of salt content per serving was more than double the range per $100 \mathrm{~g}$. Variability was apparent even in very narrow product ranges, such as french fries (Figure 1), for which there were also substantial differences between countries. Large serving sizes means that some burger and chicken products have more than $6 \mathrm{~g}$ of salt per serving, some salads have more than $7 \mathrm{~g}$, the saltiest sandwiches have $8 \mathrm{~g}$, and one particular pizza has more than $10 \mathrm{~g}$ of salt.

\section{Interpretation}

\section{Main findings}

We saw marked variability in the reported salt content of products provided by major transnational fast food companies. This was true for comparisons made between different product categories, within product categories, and between companies and countries. Although some differences are to be expected on the basis

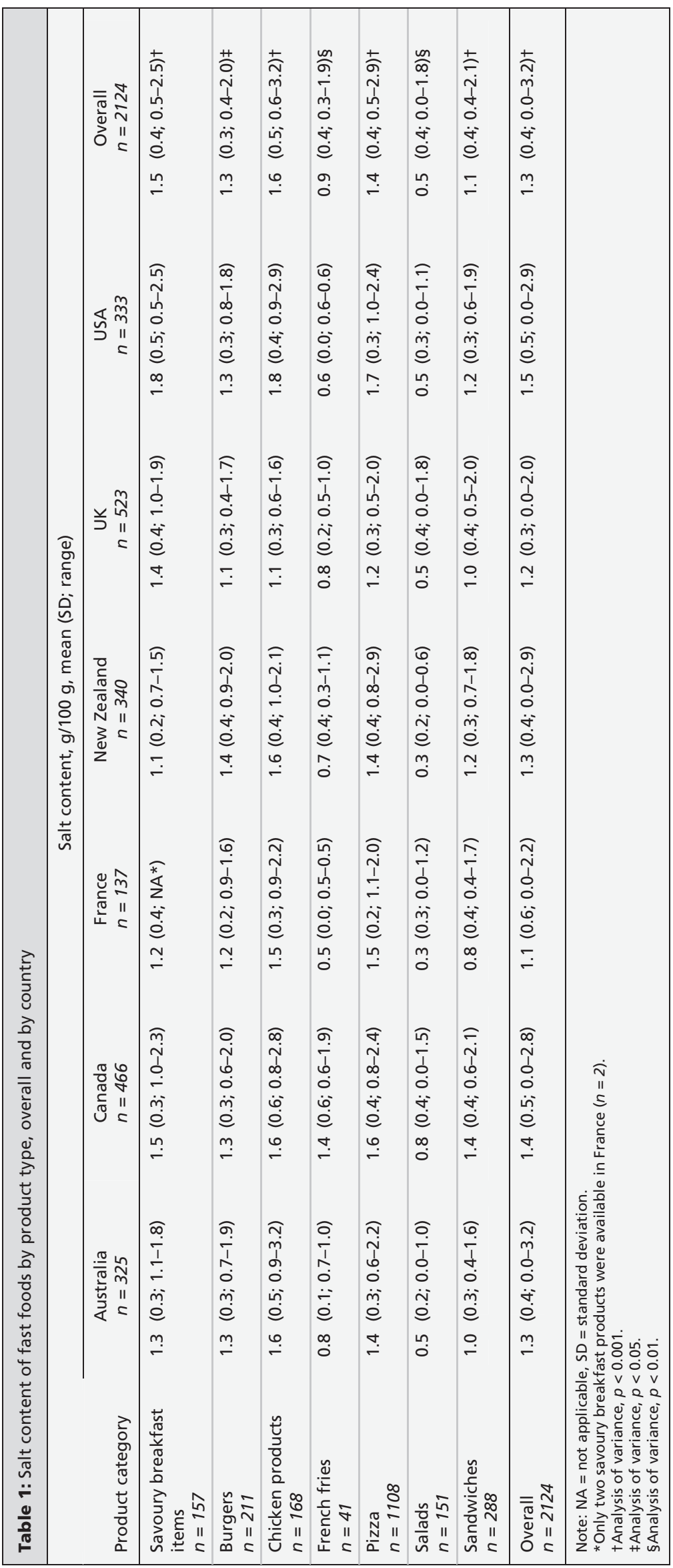


of the different types of foods served, there is a clear opportunity for widespread reformulation of products toward the lower end of the range of salt content for most categories. Technical feasibility is unlikely to be an issue for product renovation. If reductions were made incrementally over several years, fairly large cumulative de- creases in salt content could be achieved without consumers being aware of the changes in the products' formulations. ${ }^{18}$

\section{Comparison with other studies}

There is good evidence from the UK that agreement between government and industry on salt

Table 2: Salt content of the same fast food products sold in different countries

Country; serving size and salt per serving (salt per $100 \mathrm{~g}$ ), g

\begin{tabular}{|c|c|c|c|c|c|c|c|c|c|c|c|c|}
\hline $\begin{array}{l}\text { Company; } \\
\text { product }\end{array}$ & \multicolumn{2}{|c|}{ Australia } & \multicolumn{2}{|c|}{ Canada } & \multicolumn{2}{|c|}{ France } & \multicolumn{2}{|c|}{ New Zealand } & \multicolumn{2}{|c|}{ United Kingdom } & \multicolumn{2}{|c|}{ United States } \\
\hline Double Whopper & 359 & $2.9(0.8)$ & 373 & $2.5(0.7)$ & - & - & 367 & $2.7(0.7)$ & 355 & $2.3(0.7)$ & NA & 2.7 (NA) \\
\hline Double Cheese & 213 & $2.6(1.5)$ & 189 & $2.4(1.3)$ & - & - & 187 & $2.6(1.2)$ & 173 & $2.4(1.4)$ & NA & 2.5 (NA) \\
\hline \multicolumn{13}{|l|}{ Domino's } \\
\hline Hawaiian Pizza & 65 & $1.0(1.5)$ & - & - & - & - & 67 & $1.0(1.5)$ & 70 & $0.7(1.0)$ & - & - \\
\hline \multicolumn{13}{|l|}{$\begin{array}{l}\text { Kentucky Fried } \\
\text { Chicken }\end{array}$} \\
\hline Zinger Burger & 197 & $3.0(1.5)$ & - & - & 207 & $2.6(1.2)$ & 186 & $3.1(1.7)$ & NA & 3.0 (NA) & - & - \\
\hline \multicolumn{13}{|l|}{ McDonald's } \\
\hline Big Mac & 200 & $2.4(1.2)$ & 209 & $2.6(1.2)$ & 221 & $2.3(1.0)$ & 202 & $2.7(1.3)$ & 214 & $2.1(1.0)$ & 214 & $2.6(1.2)$ \\
\hline $\begin{array}{l}\text { Chicken } \\
\text { McNuggets }\end{array}$ & 98 & $1.1(1.1)$ & 114 & $1.7(1.5)$ & 107 & $1.3(1.2)$ & 88 & $1.0(1.1)$ & 105 & $0.6(0.6)$ & 95 & $1.5(1.6)$ \\
\hline \multicolumn{13}{|l|}{ Pizza Hut } \\
\hline Hawaiian Pizza & 88 & $1.3(1.5)$ & 84 & $1.0(1.1)$ & - & - & 82 & $1.1(1.3)$ & 73 & $0.8(1.1)$ & 102 & $1.5(1.5)$ \\
\hline \multicolumn{13}{|l|}{ Subway } \\
\hline Club sandwich & 212 & $1.8(0.9)$ & 240 & $2.7(1.1)$ & 238 & $1.3(0.5)$ & 220 & $2.7(1.2)$ & 254 & $2.3(0.9)$ & 247 & $2.9(1.2)$ \\
\hline
\end{tabular}

Table 3: Salt content, overall and by company, of fast foods by product type

\begin{tabular}{|c|c|c|c|c|c|c|}
\hline \multirow[b]{2}{*}{$\begin{array}{l}\text { Product } \\
\text { category }\end{array}$} & \multicolumn{6}{|c|}{ Company; salt content, g/100 g, mean (SD; range) } \\
\hline & Burger King* & Domino's & KFC & McDonald's & Pizza Hut & Subway \\
\hline $\begin{array}{l}\text { Savoury } \\
\text { breakfast } \\
\text { items }\end{array}$ & $1.4(0.3 ; 0.4-2.3)$ & - & $2.5(0.0 ; 2.5-2.5)$ & $1.4(0.4 ; 0.1-2.4)$ & - & $1.3(0.2 ; 0.7-1.6)$ \\
\hline Burgers & $1.2(0.3 ; 0.4-1.9)$ & - & $1.4(0.3 ; 0.8-2.0)$ & $1.2(0.3 ; 0.7-2.0)$ & - & - \\
\hline $\begin{array}{l}\text { Chicken } \\
\text { products }\end{array}$ & $1.8(0.7 ; 1.2-2.8)$ & $1.8(0.8 ; 1.0-3.2)$ & $1.6(0.5 ; 0.8-2.9)$ & $1.3(0.4 ; 0.6-1.9)$ & $1.5(0.5 ; 0.9-2.0)$ & - \\
\hline French fries & $1.2(0.4 ; 0.0-2.4)$ & - & $0.9(0.5 ; 0.0-3.8)$ & $0.7(0.2 ; 0.0-2.5)$ & $1.3(0.5 ; 0.3-3.5)$ & - \\
\hline Pizza & - & $1.3(0.3 ; 0.5-2.1)$ & - & - & $1.5(0.4 ; 0.6-2.9)$ & - \\
\hline Salads & $0.5(0.3 ; 0.0-0.9)$ & $0.8(0.2 ; 0.6-0.9)$ & $0.6(0.3 ; 0.0-1.3)$ & $0.6(0.3 ; 0.0-1.5)$ & $1.1(0.4 ; 0.5-1.8)$ & $0.3(0.2 ; 0.0-1.1)$ \\
\hline Sandwiches & $1.4(0.1 ; 1.3-1.6)$ & $1.2(0.5 ; 0.4-2.0)$ & $1.4(0.3 ; 0.7-2.1)$ & $1.3(0.4 ; 0.6-2.0)$ & $1.7(0.3 ; 1.3-2.1)$ & $1.0(0.3 ; 0.4-1.9)$ \\
\hline Overall & $1.3(0.5 ; 0.0-2.8) \dagger$ & $1.3(0.3 ; 0.4-3.2) \dagger$ & $1.4(0.5 ; 0.0-3.8) \dagger$ & $1.1(0.5 ; 0.0-2.5) \dagger$ & $1.5(0.4 ; 0.3-3.5) \dagger$ & $0.9(0.4 ; 0.0-1.9) \dagger$ \\
\hline
\end{tabular}


targets has driven down the salt levels of processed foods. ${ }^{19-21}$ This model would appear to have the same potential for fast foods. Indeed, in the data we present, it is apparent that mean salt levels are already lower in fast foods from the UK than from elsewhere, which may be a consequence of industry's active participation in salt reduction efforts in that country.

An approach that delivers incremental, sectorwide reductions in the salt content of all fast food products has the greatest appeal from a public health perspective, because small reductions in risk for everyone would add up to large overall benefits. ${ }^{22}$ Because large fast food companies already have dynamic ongoing programs of product reformulation, the marginal cost of incorporating salt-reduction targets should be minimal. ${ }^{23}$

In addition, the much greater variation in salt content seen when comparisons were made per serving rather than per $100 \mathrm{~g}$ is potential evidence for reducing and standardizing serving sizes. Such an approach would have the added advantage of simultaneously reducing consumption of other adverse nutrients and is one strategy advocated for addressing the obesity epidemic. ${ }^{24}$ There is clear evidence that the serving sizes of fast foods have increased substantially in recent decades, so such a change would simply represent a return to the norm. ${ }^{11,24,25}$

\section{Limitations}

Our study was based on the data provided on the companies' websites, and we relied on their veracity. Although we believe most companies report correct nutritional values, this may not always be the case. Several companies use accredited laboratories for analysis, but the limited validation data available make it difficult to know whether there are significant random or systematic errors influencing the results of those analyses. $^{26}$

\section{Conclusion}

Decreasing salt in fast foods would appear to be technically feasible and is likely to produce important gains in population health — the mean salt levels of fast foods are high, and these foods are eaten often. ${ }^{16,27}$ Governments setting and enforcing salt targets for industry would provide a level playing field, and no company could gain a commercial advantage by using high levels of salt. Extending the research to include additional countries would help test the generalizability of our conclusions.

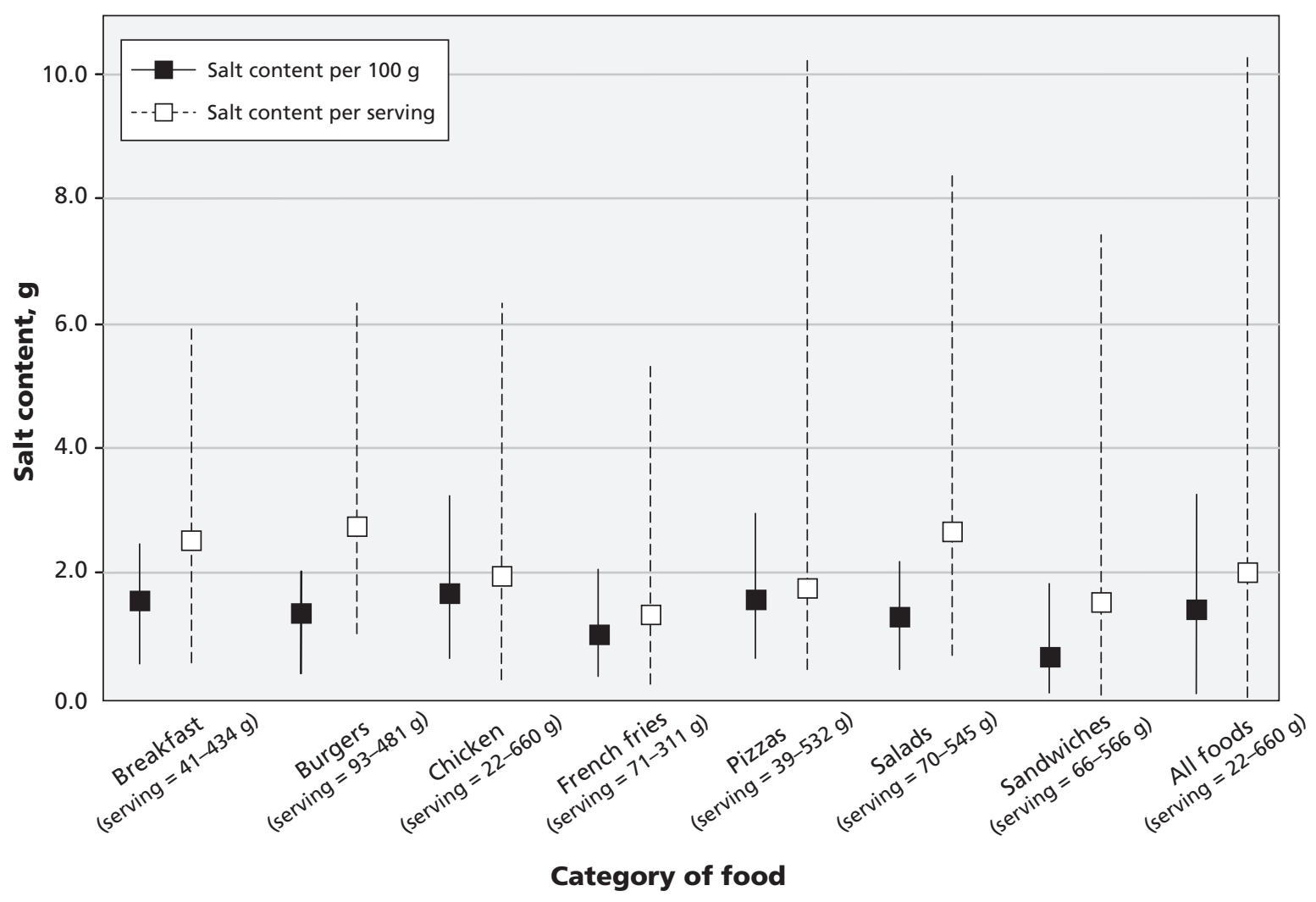

Figure 1: Mean salt content per 100 grams and per serving for fast foods by product type. Lines extending from the mean (boxes) indicate the range of values for the category. Breakfast = savoury breakfast items, chicken = all chicken products. 


\section{References}

1. Intersalt Cooperative Research Group. Intersalt: an international study of electrolyte excretion and blood pressure. Results for 24 hour urinary sodium and potassium excretion. BMJ 1988;297: 319-28.

2. Dyer A, Elliott P, Shipley M. Urinary electrolyte excretion in 24 hours and blood pressure in the INTERSALT study. II. Estimate of electrolyte-blood pressure associations corrected for regression dilution bias. The INTERSALT Cooperative Research Group. Am J Epidemiol 1994;139:940-51.

3. Asaria P, Chisholm D, Mathers C, et al. Chronic disease prevention: health effects and financial costs of strategies to reduce salt intake and control tobacco use. Lancet 2007:370:2044-53.

4. Havas S, Dickinson B, Wilson M. The urgent need to reduce sodium consumption. JAMA 2007;298:1439-41.

5. Mozaffarian D, Appel LJ, Van Horn L. Components of a cardioprotective diet: new insights. Circulation 2011;123:2870-91.

6. World Health Organization. Global status report on noncommunicable diseases 2010: description of the global burden of NCDs, their risk factors and determinants. Geneva (Switzerland): The Organization; 2011.

7. Rangan AM, Schindeler S, Hector DJ, et al. Consumption of 'extra' foods by Australian adults: types, quantities and contribution to energy and nutrient intakes. Eur J Clin Nutr 2009;63:865-71.

8. Paeratakul S, Ferdinand DP, Champagne CM, et al. Fast-food consumption among US adults and children: dietary and nutrient intake profile. J Am Diet Assoc 2003;103:1332-8.

9. Isganaitis E, Lustig RH. Fast food, central nervous system insulin resistance, and obesity. Arterioscler Thromb Vasc Biol 2005;25: 2451-62.

10. Pereira MA, Kartashov AI, Ebbeling CB, et al. Fast-food habits, weight gain, and insulin resistance (the CARDIA study): 15 year prospective analysis. Lancet 2005;365:36-42.

11. Nielsen SJ, Popkin BM. Patterns and trends in food portion sizes, 1977-1998. JAMA 2003;289:450-3.

12. Farley T. Cut the salt. Get the facts: The National Salt Reduction Initiative. New York (NY): New York City Department of Mental Health and Hygiene. Available: www.nyc.gov/html/doh/downloads /pdf/cardio/cardio-salt-nsri-faq.pdf (accessed 2010 Dec. 2).

13. Food Standards Agency. Salt reduction targets: March 2006. London (UK): The Agency; 2006. Available: www.food.gov.uk /multimedia/pdfs/salttargetsapril06.pdf (accessed 2010 Dec. 10).

14. Cobcroft M, Tikellis K, Busch JLH. Salt reduction - a technical overview. Food Aust 2008;60:83-6.

15. IBISWorld. Global Hotels and Restaurants: G4621-GL Global fast food restaurants. In: IBISWorld global industries report. IBISWorld: Santa Monica (CA); 2011.

16. O'Donnell SI, Hoerr SL, Mendoza JA, et al. Nutrient quality of fast food kids meals. Am J Clin Nutr 2008;88:1388-95.

17. Dunford E, Webster J, Barzi F, et al. Nutrient content of products served by leading Australian fast food chains. Appetite 2010;55 484-9.

18. Girgis S, Neal B, Prescott J, et al. A one-quarter reduction in the salt content of bread can be made without detection. Eur J Clin Nutr 2003;57:616-20.

19. World Health Organization. Creating an enabling environment for population-based salt reduction strategies. Geneva (Switzerland): The Organization; 2011.

20. Webster JL, Dunford EK, Hawkes C, et al. Salt reduction initiatives around the world. J Hypertens 2011;29:1043-50.

21. Wyness LA, Butriss JL, Stanner SA. Reducing the population's sodium intake: the UK Food Standards Agency's salt reduction programme. Public Health Nutr 2012;15:254-61.

22. Rose G. Strategy for prevention: lessons from cardiovascular disease. BMJ 1981;282:1847-51.

23. Bibbins-Domingo K, Chertow GM, Coxson PG, et al. Projected effect of dietary salt reductions on future cardiovascular disease. N Engl J Med 2010;362:590-9.

24. Young LR, Nestle M. Expanding portion sizes in the US marketplace: implications for nutrition counseling. J Am Diet Assoc 2003; 103:231-4.

25. Piernas C, Popkin BM. Food portion patterns and trends among US children and the relationship to total eating occasion size, 1977-2006. J Nutr 2011;141:1159-64.

26. Rose D. Hungry Jack's roasted over new burger. The Sydney Morning Herald 2009 Nov. 24. Available: www.smh.com.au /lifestyle/wellbeing/hungry-jacks-roasted-over-new-burger20091124-jenz.html (accessed 2010 Nov. 15).

27. Stender S, Dyperberg J, Astrup A. Fast food: unfriendly and unhealthy. Int J Obes (Lond) 2007;31:887-90.
Affiliations: From The George Institute for Global Health (Dunford, Webster, Woodward, Neal), The University of Sydney (Dunford, Neal), Sydney, Australia; the Department of Nutrition, University Versailles St-Quentin and A. Paré Hospital, Boulogne-Billancourt, France (Czernichow); the Department of Epidemiology (Yuan), McGill University, Montréal, Que.; Wolfson Institute of Preventive Medicine (Jenner), Queen Mary, University of London, London, UK; Clinical Trials Research Unit (Ni Mhurchu), The University of Auckland, Auckland, New Zealand; Center for Science in the Public Interest (Jacobson), Washington, DC; and Libin Cardiovascular Institute of Alberta (Campbell), the University of Calgary, Calgary, Alta.

Contributors: Elizabeth Dunford, Jacqueline Webster and Bruce Neal conceived and designed the study. Elizabeth Dunford and Wen Lun Yuan collected the data. Elizabeth Dunford, Jacqueline Webster, Bruce Neal, Wen Lun Yuan and Cliona Ni Mhurchu interpreted the data. Elizabeth Dunford, Jacqueline Webster and Bruce Neal drafted the manuscript, with input and review from all other authors. All of the authors critically revised the manuscript for important intellectual content and approved the final version submitted for publication.

Competing interests: Elizabeth Dunford is the research officer, Jacqueline Webster is the senior project manager and Bruce Neal is the Chair of the Australian Division of World Action on Salt and Health. Elizabeth Dunford and Jacqueline Webster have received funding from the World Health Organization (WHO) to develop a tool for monitoring sodium content in foods; they have received funding from Bupa Australia for the development of a mobile application for interpreting nutritional information. Jacqueline Webster has received a grant from the National Health and Medical Research Council to monitor salt intakes and sources of salt in the diet; she is a consultant for the WHO and has received funding to develop salt-reduction strategies in the Pacific Islands and Mongolia; she has received grants from the Australian Food and Grocery Council; she has received payment for lectures from Mitsubishi Tanabe Pharma Company. Sebastien Czernichow is a board member and consultant for Sanofi; he is a consultant for Unilever and received payment for developing education presentations; he has received payment for lectures from Servier. Katharine Jenner is a healthyeating coordinator for the charity The Food Chain; she is the campaign manager for World Action on Salt and Health. Cliona Ni Mhurchu is a consultant for Food Standards New Zealand; she is a member of the Food and Nutrition Working Group for the Heart Foundation of New Zealand; she has been reimbursed for travel expenses by the International Life Sciences Institute. Norm Campbell has been reimbursed for travel expenses by Boerhinger Ingelheim and has received honoraria from other academic organizations for speaking on hypertension and dietary sodium. Bruce Neal is a consultant and member of the boards for Roche Diagnostics, Takeda and PepsiCo; he has received payment for lectures or reimbursement for travel from Amgen, AstraZeneca, GlaxoSmithKline, Novartis, PepsiCo, Pfizer, the Pharmacy Guild of Australia, Sanofi-aventis, Servier and Tanabe; his institution has received funding from the Australian Food and Grocery Council, Bupa Australia, Johnson and Johnson, Merck Schering Plough, Roche Diagnostics, Servier and United Healthcare Group. No other competing interests were declared.

Acknowledgements: Elizabeth Dunford is supported by a Sydney Medical School Foundation Scholarship. Cliona Ni Mhurchu holds the Heart Foundation of New Zealand Senior Fellowship (grant no. 1380). Jacqueline Webster is supported by a Heart and Stroke Foundation Postdoctoral Research Fellowship. Bruce Neal is supported by an Australian Research Council Future Fellowship. 